\section{New products and focus on infection control and orthodontics}

\section{STAY IN CONTROL WITH COLOUR-CODED LABELS}

Positive I.D. Labelling has created a new system of colour-coded labelling to help dental practices meet the HTM 01-05 legislation. Dental practices using non-vacuum sterilisers (type N) must have a system in place to ensure that storage of sterilised instruments does not exceed 21 days.

The new labels state the date dental instruments were sterilised and the date that they need to be used by. They are also colour-coded into a four weekly cycle. This enables the dental team to see, at a glance, which instruments are approaching their 'use by' dates, so they can rotate them accordingly.

The labels are attached to sealed packaging, once items have been sterilised, using a state-of-the-art labelling gun, which prints and sticks labels in one smooth movement. The labels can be personalised to each individual practice and come in a range of sizes and formats.

The labelling gun and 22,000 each of the four-colour labels are available to dental practices for a special price of $£ 249+V A T$.

Reader response number 50

\title{
FULL STRENGTH WITHOUT DECALCIFICATION
}

Fuji Ortho LC is the first light-cured, resin reinforced glass ionomer for bracket bonding. It enables you to work more quickly while securing the full strength needed without decalcification at debonding. Fuji Ortho LC releases significant levels of fluoride and fluoride toothpastes and mouthrinses actually recharge its fluoride release capacity.

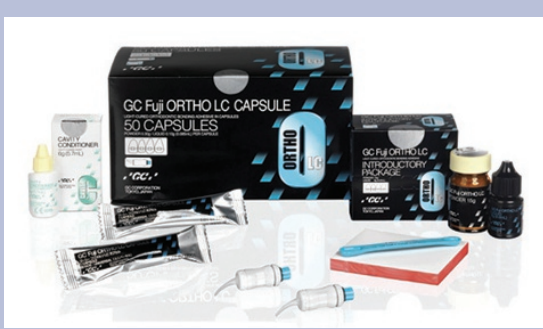

Fuji Ortho LC is moisture friendly so bonds perfectly in a wet field. It can be used with either a non-etch or etch technique and no separate bonding agent is needed. As it is less technique sensitive chairside time is significantly reduced.

Fuji Ortho LC light cures in 20-40 seconds with instant strength and the material will even set chemically in the absence of light. You can insert levelling wire during the same visit.

Advanced glass ionomer technology bonds brackets with ample strength for even the most aggressive treatment, yet is easy to remove at case completion without damaging the enamel. Reader response number 51

\section{LATEX AND ADRENALINE FREE CARTRIDGES}

The latex and adrenaline free Citanest 3\% with Octapressin Dental Injection is available in $2.2 \mathrm{ml}$ standard and selfaspirating cartridges. The absence of
Please send trade news information and illustrations to Arveen Bajaj at the $B D J$, Nature Publishing Group, The Macmillan Building, 4-6 Crinan Street, London N1 9XW. Trade news is provided as a service to readers using text and images from the manufacturer, supplier or distributor and does not imply endorsement by the BDJ. Normal and prudent research should be exercised before purchase or use of any product mentioned.

\section{A NEW GENERATION IN SOFT TISSUE REGENERATION}

Geistlich Mucograft is a resorbable 3D-collagen matrix and an alternative to autogenous soft tissue grafts, which prevents donor site morbidity due to harvesting of autogenous grafts. Geistlich Mucograft is designed specifically for soft tissue regeneration.

The 3D-matrix Geistlich Mucograft consists of a compact structure and a spongy scaffold. The compact structure provides structural integrity, stability and is easy to suture. It protects the defects from infections and allows the use of Geistlich Mucograft in open-healing situations, without the need for wound dressing. The spongy scaffold is designed to add volume to Geistlich Mucograft and to allow soft tissue ingrowth.

Geistlich Mucograft can be applied directly from the blister to the defect without any pre-treatment.

Reader response number 52

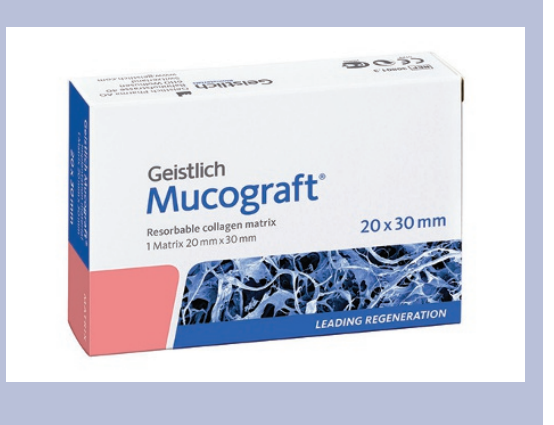

latex and adrenaline ensures patient safety and peace of mind.

It is fully compatible with patient medications where plain and adrenaline-containing solutions are not suitable and avoids the cardiovascular effects of adrenaline.

Citanest contains Prilocaine which is $40 \%$ less toxic than lidocaine yet still provides the reliable depth and duration demanded by routine dental procedures.

Reader response number 53 


\section{OFFER A LIFE-CHANGING SPLINT SOLUTION}

Available exclusively from S4S, the UK dental splint specialist, the NTItss is a prefabricated splint designed to be fitted and adjusted by dentists at the chairside.

NTI-tss splints provide an ideal solution to cases including: the prevention of symptoms associated with bruxism; the treatment of certain types of TMD; the prevention of occlusal trauma; and the prevention and treatment of chronic tension type headache and migraine pain.

The NTI-tss keeps the molars and canines from touching, offering therapeutic relief to the patient. Dentists are able to provide their patients with a potentially life-changing solution to bruxism and other related conditions in the form of an NTI-tss splint.

Reader response number 54

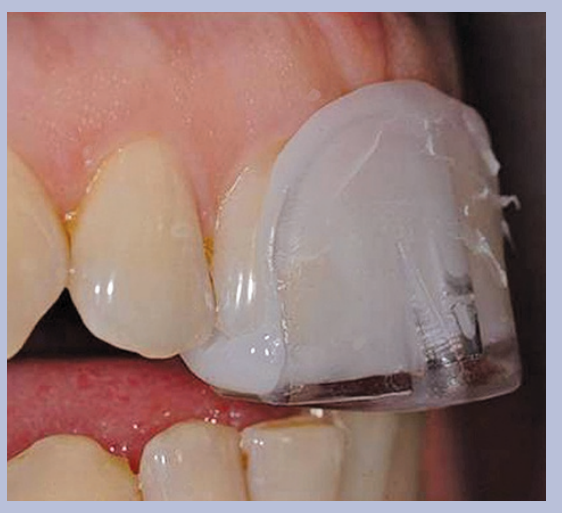

\section{A CLEAR WAY TO A PERFECT SMILE}

The Clearstep System is a range of innovative appliances designed around the aim of creating an 'invisible' solution to a range of malocclusions.

Organised into five distinct elements, the system has the flexibility to help treat extrusion, intrusion, de-rotation, extraction and non-extraction cases, orthopaedics and buccal settling.

Based on the patient information provided by the clinician, the OPT Laboratory \&t Diagnostic Facility provides treatment planning individually tailored to meet the needs of the patient. Clinicians have access to an expert team at every stage of the treatment plan.

\section{LONG TERM RETAINER WIRE STABILITY}

StarFlow from Danville Materials ensures long-term stability of orthodontic treatment.

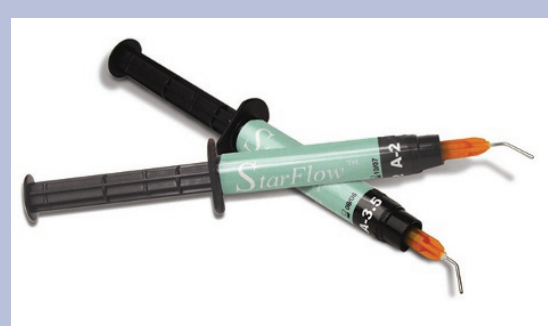

The Clearstep System also offers patients an easy solution to maintaining oral health. With the clear removable appliances a normal cleaning regimen can still be maintained, allowing access for brushing and interdental cleaning.

\section{Reader response number 55}

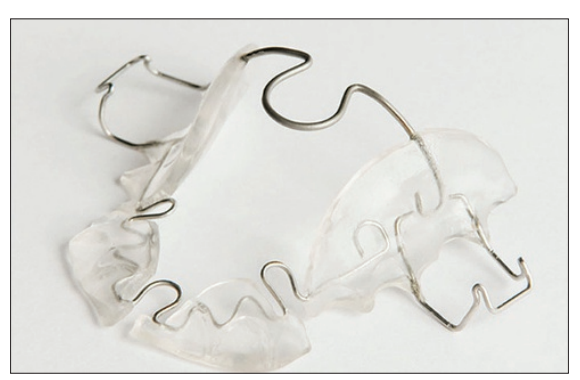

StarFlow makes easy work of bonding retainer wires. This super low viscosity flowable composite resists slumping and gravitational forces, staying in place until you are ready to permanently light-cure your retention.

Available in $5 \mathrm{gm}$ and $1 \mathrm{gm}$ single patient use syringes, StarFlow also provides long-term fluoride release and has the highest compressive strength of any flowable composite available, so it is unlikely to break or shear once placed.

Reader response number 56

\section{FAST, EASY IMAGE PROCESSING}

The digitally based system VistaScan Mini is a miniature version of the popular VistaScan. The footprint of the unit is smaller than a sheet of A4 paper so now you can change from analogue to digital without having to house bulky equipment in your surgery.

VistaScan Mini is easy to operate; after exposure the image plates are slotted into a scanner. The image is copied and stored, cleaned then returned ready for re-use. The image is available to view in about eight seconds.

Advanced software allows image enhancement and manipulation so that detail can be viewed at higher resolution. Storage is made simpler by linkage to the practice management software enabling allocation to patient records. This also allows easy image comparison over time.

Reader response number 57

\section{FLUORIDE RELEASING LUTING CEMENT}

Riva Luting is a self curing, conventional glass ionomer luting cement with extremely high long term fluoride release to inhibit enamel demineralisation at orthodontic band margins.

Providing a strong bond to metal bands and enamel, Riva Luting adheres directly to tooth tissue by the interaction of polyacrylate ions and hydroxyapatite crystals.

Riva Luting has a 'snap set' property that shortens chair time and ensures there is early resistance to water. It also has very low water solubility to ensure resistance to dissolution.

It is available in boxes of 50 capsules or in powder liquid kits.

Reader response number 58

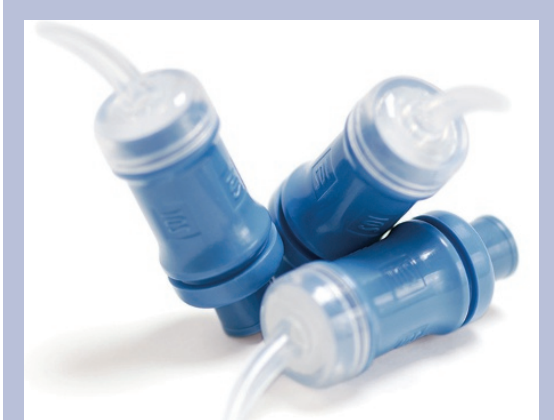




\section{LOG ON AND REMOVE IT HEADACHES}

BaseDiary is a new generation webbased management tool tailored specifically to dental professionals.

From making an appointment to generating an image, finding patient-specific data, X-rays and correspondence crucial to your business, BaseDiary is effective, consistent and efficient and enables you to be appropriately organised.

Hosted at a secure data warehouse in the UK, you simply log on to your
BaseDiary account in the morning. BaseDiary takes away almost all IT headaches and enables you to focus on your business.

BaseDiary works with any broadband connection, MACs and PCs and you do not need to upgrade your equipment. There is no contract and costs just £79.99 per month per site with unlimited users per site.

Reader response number 59

\section{THE WORKHORSE DENTAL COMPRESSOR}

JUN-AIR's OF302 dental compressor is HTM 2022 compliant, providing clean, dry air for both instruments and patients. It is also quiet in operation, rated for continuous duty and low maintenance with a long life expectancy - in fact, many units are still in operation after 25 years. The best selling $2 \mathrm{xOF} 302-40 \mathrm{BD} 2$ is the choice for up to three surgeries and is considered the 'workhorse' of dental practices.

All compressors can be housed in a range of cabinets to reduce noise levels to as low as $47 \mathrm{~dB}(\mathrm{~A})$, allowing them to be located within the surgery.

Reader response number 60

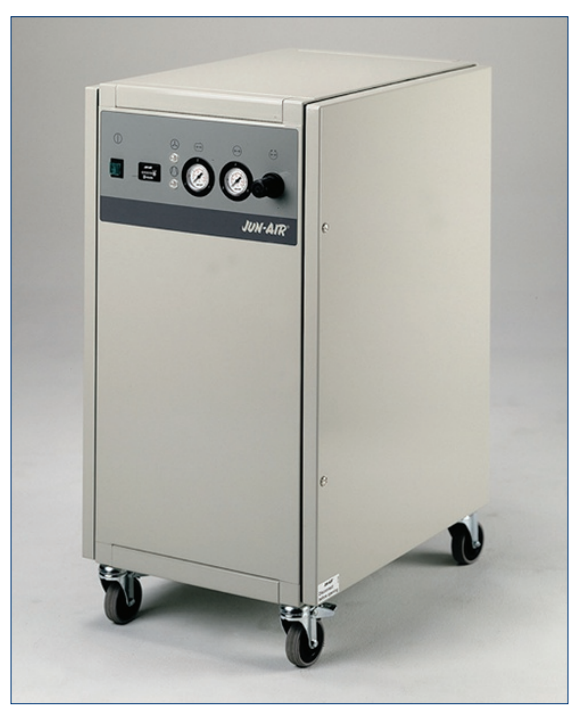

\section{INSTRUMENT DECONTAMINATION ONLINE}

Eastwood Park Training is launching a unique online dental instrument decontamination training course.

This new programme will assist dental practices in complying with the HTM 01-05 regulations, as well as gain verifiable CPD.

This flexible online course is ideal for NHS and private dental practices and hospitals as learning can take place at work or at home, reducing time away from the surgery and enabling individuals to work at their own pace.

The course is modular allowing staff to learn and develop all of the regulatory requirements relating to HTM 01-05 and includes two hours of verifiable CPD.

Reader response number 61

\section{HIGH PERFORMANCE MOUTHWEAR}

Under Armour Performance Mouthwear uses the latest technology and is custom-fitted for athletes and sportspeople by dentists.

Available as a contact or non-contact mouthpiece, the unique patented tech- nology relieves pressure on the temporomandibular joint (TMD). As a result, the body's production of the stress hormone cortisol is reduced, enabling greater athletic performance.

Reader response number 62 


\section{KEEP YOUR WORKSTATION CLEAN AND INFECTION-FREE}

Introdent have commissioned a new washable keyboard and mouse which

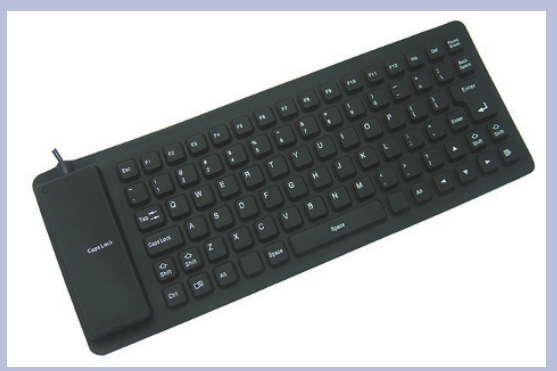

incorporate disinfectant nano silver technology into the structure of their build material.

Introdent enables your practice's work station to be infection control efficient, from under $£ 40$. It is easy to meet the latest standards in infection control with these simple USB plug in and play keyboards and mice.

Reader response number 63

\section{QUICKLY DISSOLVES PROTEINS}

Dento-Viractis has been designed specifically to remove debris from hand instruments and surgical equipment prior to sterilisation. It is particularly useful in the removal of pus and blood.

Dento-Viractis 55 quickly dissolves proteins due to its enzymatic action. This bacterial, fungicidal and virucidal product with a grapefruit aroma is available exclusively from Dental Sky in either a $2 \mathrm{~kg}$ or $5 \mathrm{~kg}$ bucket or $50 \mathrm{uni}$ doses of $15 \mathrm{~g}$ each.

Reader response number 66

\section{ANTIBACTERIAL UPHOLSTERY}

In line with current infection control guidelines, all Plinth 2000 couch coverings are vinyl, washable, stain resistant and capable of withstanding disinfection with a chlorine-based product.

Most of its standard upholstery grades incorporate a patented antibacterial additive, which provides longlasting effectiveness against MRSA, C.Diff, E.coli and other harmful bacteria and is also resistant to mould and odours.

One area of particular risk is upholstery damage, through cuts, tears or poor cleaning technique. Plinth recommends regular inspection and servicing, with the option of replacing damaged vinyl as soon as any problem occurs. Plinth 2000 has designed its couch upholstery for ease and speed of replacement. It also offers the option of upgrading older models to antibacterial upholstery.
Plinth 2000 accessories include paper roll holders, tailor-made plinth covers and foot controls for electric height adjustment.

\section{Reader response number 64}

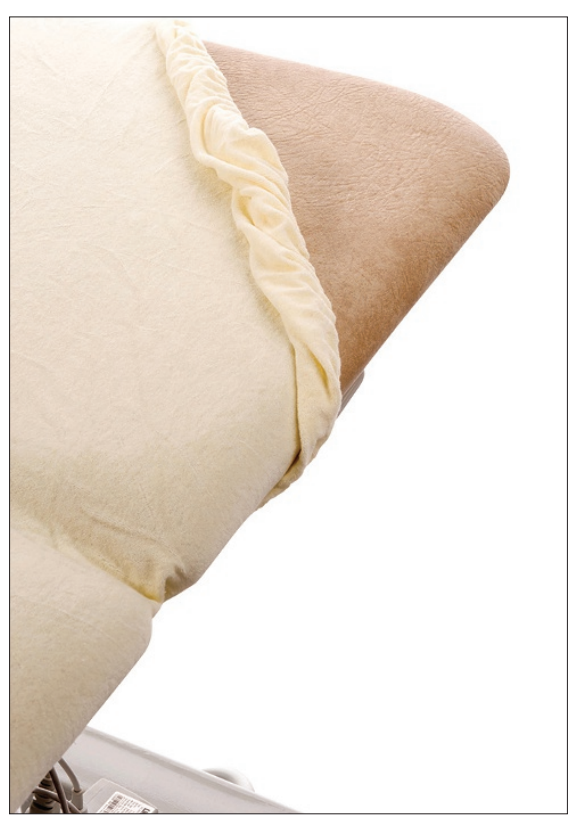

\section{SENSITIVE SURFACE CLEANER}

mikrozid sensitive from schülke is a CE marked alcohol free surface cleaner and disinfectant that is kind on delicate surfaces and tough on infection in the dental practice.

Available in liquid forms and wipes, mikrozid sensitive can be used on artificial and natural leather, perspex/plexiglas and soft PVC, making it ideal for use on patient treatment units, dental chairs, operating tables and work surfaces.

Reader response number 67

\section{IMPERVIOUS CABINETRY}

Tavom offer the ultimate in style, hygiene and organisation with all cabinetry and units HTM 01-05 compliant, easy to clean, and impervious to wear.

Robust and strong, the entire range of Tavom cabinetry is ideal for a demanding environment and features clean lines and innovative design such as integrated stainless steel sinks. Not only are they attractive but they eliminate minute corners and crevices that may harbour dust and encourage bacterial growth.

\section{Reader response number 68} removes any residue and any remaining physiological liquid that may be sitting in your handpiece. It is recommended that you wipe the outer surface of your handpiece with Aquacare to remove any saline deposits. You can then lubricate and sterilise as usual.

Reader response number 65

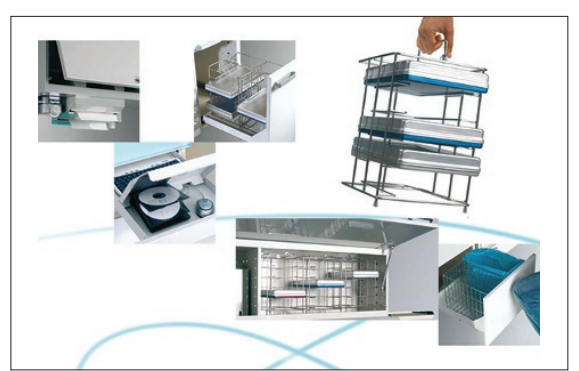

